\title{
Effect of Sodium Selenite on Testicular Damage Induced by Cisplatin in Adult Male Rats
}

Dilek Burukoglu Donmez* and Seren Bozdoğan

Department of Histology and Embryology, Faculty of Medicine, Eskisehir Osmangazi University, Eskisehir, Turkey

*Corresponding author: Dilek Burukoğlu Donmez PhD, Department of Histology and Embryology, Faculty of Medicine, Eskisehir Osmangazi University, Eskisehir, Turkey, Tel: 90-222-239-2979-4464; E-mail: dburukoglu@yahoomail.com

Received date: July 1, 2014 Accepted date: August 23, 2014, Published date: August 30, 2014

Copyright: (c) 2014 Burukoğlu D, et al. This is an open-access article distributed under the terms of the Creative Commons Attribution License, which permits unrestricted use, distribution, and reproduction in any medium, provided the original author and source are credited.

\begin{abstract}
Cisplatin is an established chemotherapeutic substance commonly used in the treatment of cancer. Several reports have been published on its antineoplastic activity and toxicity however, no details are available on its noxious effects on the genital system organs such as testes. Another interesting element Selenium and its derivatives including Sodium selenite are reported to form the active center of glutation peroxidase which has antioxidant properties involved in antioxidant balance of the cells and in lipid peroxidation. This study was aimed to explore the effects of selenium against the damage caused in testes of rats by Cisplatin treatment. Sprague-Dawley rats 28 in number were randomly allotted to different standard and treatment groups. All the animals in different experimental groups were maintained under controlled standard conditions. The results clearly demonstrated that Cisplatin treatment decreased the weight of testes as well as the body weight of rats. Furthermore, it damaged seminiferous tubules and cells in testes of animals in the treatment groups, and halted the process of spermatogenesis. Selenium treatment reduced the damage caused by Cisplatin treatment. The results of the present study were substantiated by detailed histopathological investigations
\end{abstract}

Keywords: Cisplatin; Selenium; Rat; Testis

\section{Introduction}

Cancer demonstrates itself with uncontrolled reproduction, diffusion, and metastasis of normal cells leading to death $[1,2]$. Current reports from the U.S. Centre for Disease Control and Prevention 2014 ranked cancer to be the second leading cause of death after heart diseases. . Various reports on newly introduced anti-cancer drug products and surgical interventions could in some cases eliminate the growth of cancer and reproduction of tumor cells.. However, due to structural resemblances between normal cells and tumor cells, antineoplastic chemotherapy could damage the normal cells as well [1]. In terms of its structure, Cisplatin is an organo platinum compound that does not resemble other antineoplastic drugs in terms of its structure. Cisplatin is commonly used in the treatment of numerous solid tumors predominantly the tumors of head-neck, esophagus, testes, bladder, prostate, cervix, ovary cancers, and estrogenic sarcoma, neuroblastoma, and small-cell lung cancer [3]. It is well known that, chemotherapy with antineoplastic drugs used to cause significant toxic effects on gastrointestinal tract and on the fast growing cells of the hematopoietic system in addition to genital system organs like testes [4].

In general, due to high mitotic activity, testis germinal epithelial cells are susceptible to most of the cytotoxic chemotherapeutics. Cisplatin treatment was found to cause testicular damage due to its harmful attack on spermatogenic cells and Sertoli cells [3,5-7]. Furthermore, Cisplatin was established to cause functional disorders in Leydig cells and induced infertility because of irreparable damage caused to the stem cells colony [6]. The most susceptible cells were actively dividing spermatogonium and spermatocytes up to preleptotene phase. However, the mechanism of Cisplatin induced harm to testicular cells is yet poorly understood $[6,8]$

Selenium is an element found in Group 6A of the periodic table. It is present in air, soil, rocks, and in water as molten [9-11]. It is found to be fairly safe and belongs to the group of essential trace elements needed for proper health and nutrition [12]. Studies showed that Se is required for normal male reproduction functions. Blood Se levels decreased in patients undergoing Cisplatin treatment which demonstrated Se to provide protection against Cisplatin induced harmful effects $[4,5,13]$. There is still a need for understanding the effects of Cisplatin activity and its mechanism of action and to further investigate the role of Se in combination with anticancer drugs. In this study, we aimed to investigate the protective effect of Se on rat testes tissue damaged by Cisplatin treatment. The changes observed were substantiated by detailed histopathological study.

\section{Material and Methods}

A total of 28 adult male Sprague Dawley rats aged 4 months; weighing about 250-300 $\mathrm{g}$ were used in the current study. Experimental animals (7 rats each) were divided in to 4 groups: Control, Cisplatin, Selenium, and Cisplatin+Selenium group.. The rats in control group were administered (i.p.) normal saline once a day for 7 days. In all cases drug dose was adjusted according to body weights of rats. Animals in Ciplatin treatment group received a single dose of 7 $\mathrm{mg} / \mathrm{kg}$ Cisplatin on the first day. Selenium group was given $1 \mathrm{mg} / \mathrm{kg} \mathrm{Se}$ (i.p.) once daily for 7 days. Rats in the combined Cisplatin+Se treatment group received a single dose of $7 \mathrm{mg} / \mathrm{kg}$ Cisplatin (i.p.) on the 1 st day followed by $1 \mathrm{mg} / \mathrm{kg}$ Se (i.p.) treatment once a day for 7 days. At the end of the experiment, left side testes of each rat were dissected out and immersed in Bouin's solution for tissue follow-up procedure. On the other side, the right side testes of each rat were 
removed and fixed in $\% 10$ neutral formalin. Paraffin block preparations were made and $5 \mu$ slices were cut with American microtome for routine histological procedures. Microscopic analyses of sections obtained from the left testis were conducted after staining with Hematoxylin+Eosin and Periodic Acid Schiff + Hematoxylin. On the other side, sections obtained from the right testes were stained by TUNEL method for the purpose of establishing apoptotic cells. Images representing the groups were obtained by analyzing the preparations under Olympus BX51 light microscope equipped with DP 70 digital camera. The lens magnification power in each case was noted for further investigations and making microphotographs for reference.

\section{Statistical Method}

Analysis of the data was conducted with SigmaStat 3.5 software pack. Body weight levels were compared by two-way repetitive measurements (single-factor repetition) variance analysis. Holm-Sidak test was used for multiple comparisons. Total testes weights were compared by one way variance analysis. Histological scorings were compared by Kruskal-Wallis one way variance analysis. Tukey's range test was used as a multiple comparison test.

The difference between the two groups was considered to be statistically significant at $\mathrm{P}<0.05$.

\section{Results}

\section{Control group}

In testes, basal membrane, seminiferous tubule structures, interstitial region, all Leydig cells found within, and veins were observed to be in normal shape and structure. Tubule wall was found with regular spermatogenesis having normal structure along with its Sertoli cells, quite significant spermatogonia, and spermatogenic serial cells. All details were observed for comparison (Figure 1a-d).

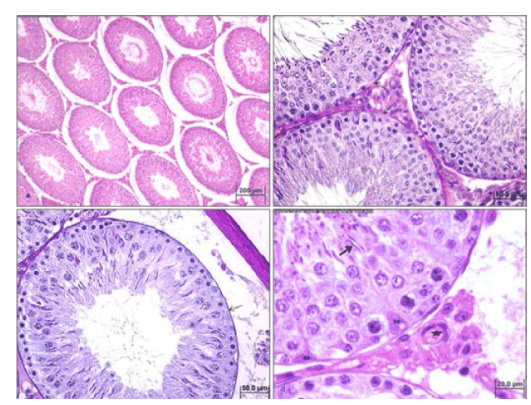

Figure 1: Control group: Testes seminiferous tubule structures with normal appearance, spermatogenic cells, Sertoli cell (Se), spermatogonium $(\mathrm{s})$, spermatid $(\rightarrow)$, tunica albuginea (ta), PAS positive basal lamina structure (thick arrow), interstitial region and the structures it contains, Leydig cell (), and venous structure $\left({ }^{*}\right)$ are observed here. (a-d) (HE, PAS+H), (bar: $200 \mu \mathrm{m}$, bar: $50.0 \mu \mathrm{m}$, bar: $20.0 \mu \mathrm{m})$.

The normal values were noticed in all specimens of the control group rats after TUNEL staining conducted in order to determine DNA fragmentation (Figure 2a).

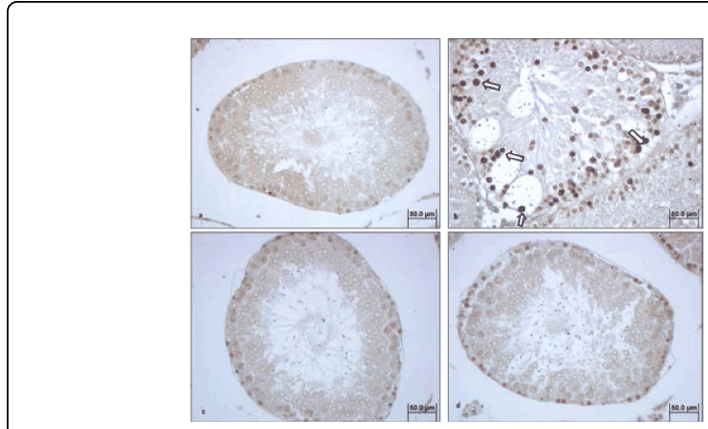

Figure 2: (a) In control group tests that were applied TUNEL method, all the structures appear to be TUNEL negative. (b) In cisplatin group, TUNEL positive stained cells stand out especially in spermatogonium and primary spermatocytes. (c) In selenium group, there are cells demonstrating TUNEL negative staining similar to control group and (d) cells demonstrating reduced TUNEL positive staining in cisplatin+selenium group (bar: 50.0 $\mu \mathrm{m}, \mathrm{TUNEL})$.

\section{Cisplatin group}

In the specimens from Cisplatin treatment group, there were highly significant $(\mathrm{P}<0.001)$ degenerative changes and cellular losses in seminiferous tubule wall in testes as compared to the normal control (Figure 3a-d). There statistically significant $(\mathrm{P}<0.01)$ changes in the multinuclear structure in spermatogenic cells, predominantly in primary spermatocyte cells in the walls of some tubules and necrotic spermatogenic cells with eosinophilic cytoplasm and pyknotic nucleus were observed (Figure 3c). In addition, thinned tubule wall along with basal membrane were established to be separated from the tubule wall (Figure 3b,c). Furthermore, both vacuolization and tubular atrophy were observed in tubule wall (Figure $3 \mathrm{c}$ ). In the interstitial region there was venous congestion (Figure 3a,b). Spermatogonium, primary spermatocyte, and spermatid cells that demonstrated TUNEL positive staining in preparations, showed the presence of apoptotic cells (Figure 2b).

\section{Se group}

It was observed in testes that seminiferous tubule, basal membrane structure, and interstitial region showed a structure similar to control group. The spermatogenesis was maintained normal. Spermatogenic cell series in seminiferous tubule wall, spermatogonium, primary spermatocytes, spermatid cell, and Sertoli cell were found normal and comparable to the untreated control (Figure 4a-d). All the changes in different parameter under investigation were found to be statistically non-significant as compared to the normal control. Leydig cells found in the interstitial region and venous structures were also found normal (Figure 4c,d). Preparations that were stained by TUNEL method in order to determine apoptotic cells were established to be similar to control group in terms of TUNEL reaction (Figure 2c).

Considering the body weight analysis, a significant difference was not observed when compared the body weights of rats before and after the experiment in control and Se groups Body weight in the group that was administered cisplatin was established to be higher before the experiment compared to post-experiment; a statistically significant difference was observed $(\mathrm{p}<0.05)$. 


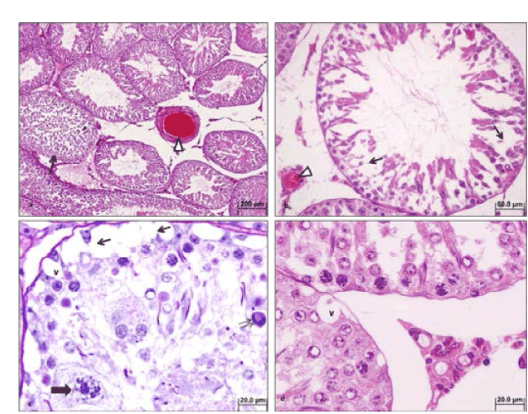

Figure 3: Cisplatin group: Dense degenerations in spermatogenic cells in seminiferous tubule wall, cellular losses in tubule wall, vacuolization (v) and separations from basal membrane by breakage $(\rightarrow)$, are observed. In addition, venous congestion () stands out in interstitial region. Degenerative changes are observed in primary spermatocyte cell in a few tubules (thick arrow) and necrotic cell structure with pyknotic nucleus and eosinophilic cytoplasm (=) also stands out. (bar: $200 \mu \mathrm{m}$, bar: $50.0 \mu \mathrm{m}$, bar: 20.0 $\mu \mathrm{m}, \mathrm{HE}, \mathrm{PAS}+\mathrm{H})(\mathrm{a}-\mathrm{d})$.

In the group that was administered cisplatin+Se, post-experimental body weights were established to be lower compared to preexperiment; a statistically significant difference was observed $(p<0,05)$ (Figure 6). When compared post-experimental body weights between the groups, significant differences were observed between Se and cisplatin and also between control and cisplatin groups $(\mathrm{p}<0,05)$. The difference was also higher in cisplatin+Se and cisplatin groups, however, a statistically significant difference was not observed $(\mathrm{p}>0,05)$. A significant difference was not observed between cisplatin $+\mathrm{Se}$ and Se, cisplatin+Se and control, and Se and control groups $(\mathrm{p}>0,05)$ (Figure 6). When assessed statistically the total testicle weights between groups, a significant difference was not observed. However, it was established that cisplatin group had a lower total testes weight compared to control, cisplatin+Se, and Se groups, but that it was not statistically significant ( $\mathrm{p}=0.073$ ) (Figure 7).

\section{Cisplatin + Se group}

In combined Cisplatin+Se treatment group there were lesser tubules in testes as compared to the untreated control group rats. However, there was a significant decrease $(\mathrm{P}<0.01)$ as compared to the Cisplatintreatment group in the tubular damage, spermatogenic cells, and spermatogenesis. The spermatogenesis was established to continue. In rats that were maintained on Cisplatin+Se treatment showed lesser $(\mathrm{P}<0.01)$ degenerative changes as compared to Cisplatin treatment group. It is worth mentioning that in the Cisplatin+Se combined treatment group the spermatocytes recovered (Figure 5a-d). The structure of basal membrane that was PAS positive stained around the tubule was observed to be normal (Figure 5b,c). Leydig cells were observed to be closer to normal in interstitial region (Figure $5 \mathrm{~d}$ ). The results of TUNEL method revealed significant decrease $(\mathrm{P}<0.05)$ in apoptotic cells as compared to Cisplatin treatment group. Seminiferous tubule epithelium resembled the normal control and Se group in terms of appearance (Figure 2d). Changes in body weight: i.e. - pre-treatment body weight and post-treatment body weight and as compared to the control group rats also the differences in weight of testes, etc.

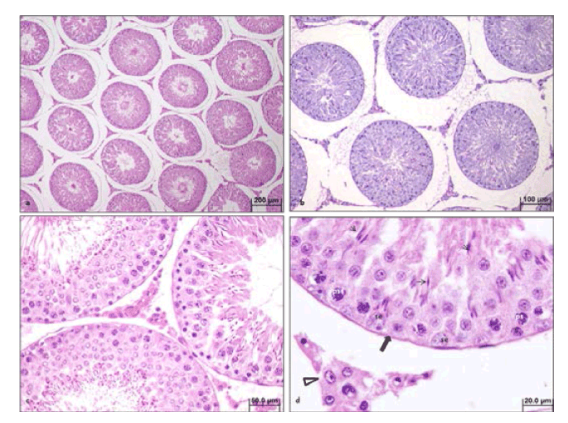

Figure 4: Selenium group: Testes seminiferous tubule structures with normal appearance, spermatogenic cells, Sertoli cell (Se), spermatogonium (s), primary spermatocyte (ps), and spermatogenesis that continues with spermatid $(\rightarrow)$ are observed. PAS positive basal lamina structure (thick arrow), interstitial region and Leydig cell () are seen here. (a-d) (HE, PAS+H), (bar: $200 \mu \mathrm{m}$, bar: $100 \mu \mathrm{m}$, bar: $50.0 \mu \mathrm{m}$, bar: $20.0 \mu \mathrm{m})$.

\section{Discussion and Conclusion}

Spermatogenic cells are quite susceptible to deteriorating effects of chemotherapeutic drugs and they can lead to infertility by causing irreparable damage in stem cell colonies [14]. In a study by Zhang et al. on Balb/c mice, it was observed that apoptosis was induced in germ cells depending on the dose of cisplatin they administered. Cisplatin treatment affected the maturing process of cells in spermatogenic series, reduced the spermatogenesis, and influenced fertility by causing azoospermia [7]. In another study cisplatin administration was demonstrated to exert spermatogenic cell loss in seminiferous tubule epithelium [15]. In addition, a decrease in body weight and testicular weight occurred. In another study it was established that the apoptosis target was spermatocytes in the group treated with $5 \mathrm{mg} / \mathrm{kg}$ Cisplatin [6]. However, in the present study apoptosis was diffused in spermatogonia, spermatocytes, and spermatids in seminiferous tubule in the group treated with $7 \mathrm{mg} / \mathrm{kg}$ dose level.

Earlier, it was discovered that body and testicular weights reduced by ethanol treatment effect. When Se was administered in combination with ethanol, the reduction in body weight and testicular weight were decelerated [16]. Cd treatment induced lipid peroxidation was reduced by Se treatment [17]. Based on the results of the present study, Se deficiency caused deteriorations in testes histology as a result of stimulating apoptosis and also of the inability to balance lipid peroxidation. Consequently, in this study, it was established that Cisplatin was toxic for testicular tissue and it deteriorates the histological structure.. Being essential mineral with antioxidant effect, Selenium was observed to significantly prevent the said damage induced by Cisplatin in testes. 
Page 4 of 4

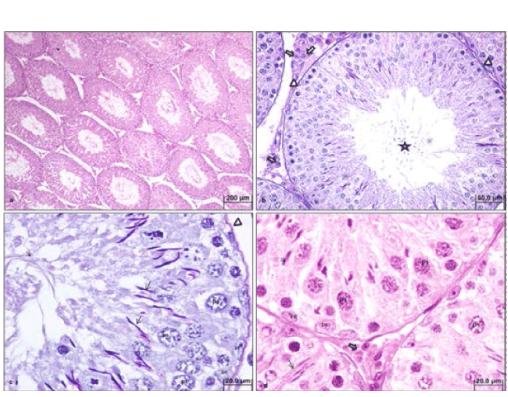

Figure 5: Cisplatin+Selenium group: Near normal maintained seminiferous tubule structures in testicular tissue, spermatogenic cells, Sertoli cell (Se), spermatogonium (s), primary spermatocyte $(\mathrm{ps})$, spermatid cell $(\rightarrow)$ along with spermatogenesis that continue in numerous tubules stand out. PAS positive basal lamina structure (), interstitial region, and Leydig cell (thick arrow) are observed. (a-d) (HE, PAS+H), (bar: $200 \mu \mathrm{m}$, bar: $50.0 \mu \mathrm{m}$, bar: $20.0 \mu \mathrm{m}$ ).

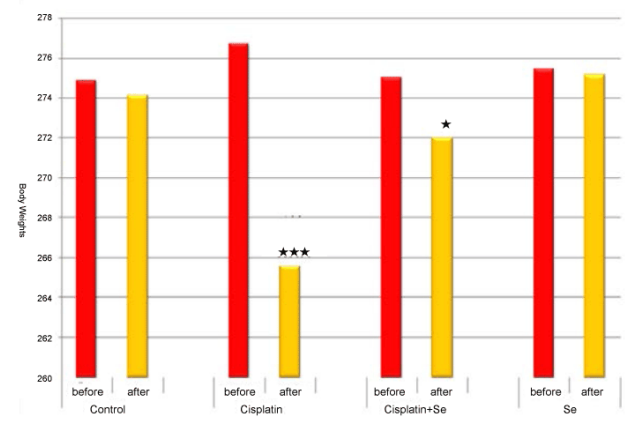

Figure 6: Pre- and post-experimental body weight differences between rats $\left(\mathrm{p}<0.05=^{*}\right)\left(\mathrm{p}<0.001={ }^{* * *}\right)$

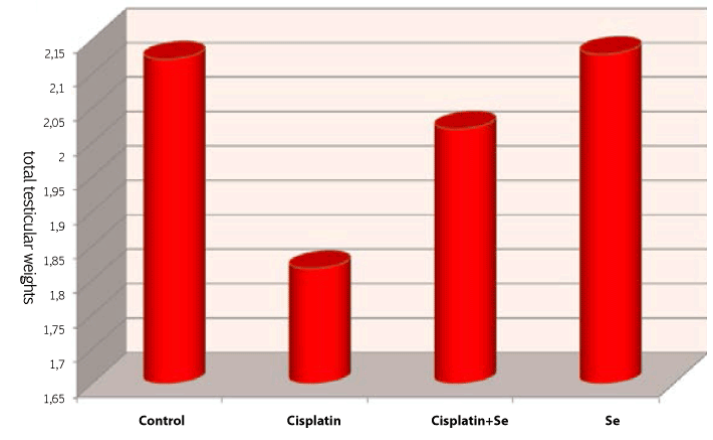

Figure 7: Comparison of total testicular weights of rats according to experiment groups.

\section{References:}

1. Kayaalp SO (2002) The principles of cancer chemotherapy and antineoplastic drugs, Rational Therapy in Terms of Medical Pharmacology, Feryal printing, Ankara.

2. Salmon SE, Sartorelli AC (2001) Cancer chemotheraphy, Basic and Clinical Pharmacology, San Francisco

3. Antunes LM, Darin JD, Bianchi Nde L (2001) Effects of the antioxidants curcumin or selenium on cisplatin-induced nephrotoxicity and lipid peroxidation in rats. Pharmacol Res 43: 145-150.

4. Kantar M, Tarladaçalisir Y, Uygun M (2007) The protective effects of vitamin $\mathrm{E}$ in cisplatin nephrotoxicity; light and electron microscopic study Type Research Journal, Trakya University Medical Faculty, Edirne, Turkey.

5. Hu YJ, Chen Y, Zhang YQ, Zhou MZ, Song XM, et al. (1997) The protective role of selenium on the toxicity of cisplatin-contained chemotherapy regimen in cancer patients. Biol Trace Elem Res 56: 331-341.

6. Seaman F, Sawhney P, Giammona CJ, Richburg JH (2003) Cisplatininduced pulse of germ cell apoptosis precedes long-term elevated apoptotic rates in C57/BL/6 mouse testis. Apoptosis 8: 101-108.

7. Zhang X, Yamamoto N, Soramoto S, Takenaka I (2001) Cisplatininduced germ cell apoptosis in mouse testes. Arch Androl 46: 43-49.

8. Sawhney P, Giammona, CJ, Meistrich, ML, Richburg JH (2005) Cisplatin-induced long-term failure of spermatogenesis in adult C57/ B1/6J mice. J. Androl. 26: 136-145.

9. Sakr S A, El-Abd F (2009) Selenium induced oxidative stress, histological and histochemical alterations in testis of albino rat. Journal of Applied Sciences 2: 307-317.

10. Mohamed S A, El-Gerbed (2013) Histopathological and ultrastructural effects of methyl parathion on rat testis and protection by selenium. Journal of Applied Pharmaceutical Science 3 : 53-63.

11. Karaaslan FJ (2009) Ethane dimethyl sulfonate in rats with adult males testicular damage created on the effect of sodium selenite, Master Thesis, Institute of Health Sciences ESOGÜ, Histology and Embryology, USA, Eskisehir

12. Helmenstine AM (2014) Selenium Facts: Selenium chemical and Physical properties. Chemistry Education, overview and resources.

13. Narayana K, Al-Bader M, Mousa A, Khan KM (2011) Molecular effects of chemotherapeutic drugs and their modulation by antioxidants in the testis. Eur. J. Pharmacol. 674: 207-216

14. Perk H, Soyupek S, Oksay T (2005) Erkek infertilitesine neden olan fiziksel ajanlar, ilaçlar ve toksinler. Süleyman Demirel Üniversitesi Tip Fakültesi Üroloji ABD Infertilite Dergisi

15. Azu OO, Duru FIO, Osinubi AA, Oremosu AA and Noronha CC, et al. (2010) Histomorphometric effects of Kigelia africana (Bignoniaceae) fruit extract on the testis following short-term treatment with cisplatin in male Sprague-Dawley rats. Middle East Fertility Society Journal 200-208.

16. Swathy SS, Panicker S, Indira M (2006) Effect of exogenous selenium on the testicular toxicity induced by ethanol in rats. Indian J Physiol Pharmacol 50: 215-224.

17. Yiin SJ, Chern CL, Sheu JY, Lin TH (1999) Cadmium induced lipid peroxidation in rat testes and protection by selenium. Biometals 12: 353-359. 